\title{
Algoritma Dijkstra untuk Penentuan Jarak Tempuh Terpendek Pengantaran Katering Pabrik
}

\author{
THETA DINNARWATY PUTRI, WINARNO SUGENG, EKA SAFITRI
}

\author{
Program Studi Informatika Institut Teknologi Nasional Bandung \\ Email: theta@itenas.ac.id
}

Received 25 Oktober 2020 | Revised 11 November 2020 | Accepted 30 November 2020

\begin{abstract}
ABSTRAK
Algoritma Dijkstra digunakan untuk menemukan jalur terpendek antara titik pada graf dan persamaan Haversine digunakan untuk mengukur jarak dari lokasi awal menuju lima lokasi tujuan yang mana lokasi tersebut merupakan pabrik yang berada di kota Cikarang dan lokasinya ada di sekitaran penyedia rumah catering. Perhitungan dilakukan setelah sistem mendapatkan koordinat latitude dan longitude pengguna dan lokasi pabrik yang dituju. Pada penelitian ini, lokasi pengguna dan lokasi pabrik dilakukan di kota Cikarang. Sistem mampu menampilkan prediksi jarak dan waktu tempuh untuk rekomendasi dari urutan lima pengantaran dengan penerapan metode algoritma Dijkstra dimana proses yang dilakukan sistem adalah memperhitungkan jarak menggunakan Haversine Formula, sehingga didapatkan waktu tempuh berdasarkan parameter kemacetan. selain itu API mampu memvisualisasikan rute setiap tujuan dari titik lokasi katering.
\end{abstract}

Kata kunci: Dijkstra, Formula Haversine, PHP, Jarak terpendek, Kecerdasan Buatan.

\section{ABSTRACT}

The algorithm is used to find the shortest path between points on a graph. The Haversine formula is used to measure the distance from the initial location to the five destination locations where the factory is located in Cikarang and the location is around the location catering house. Calculations are carried out after the system gets the user's latitude and longitude coordinates and the intended factory. In this study, the location of the user and the location of the factory were carried out in the city of Cikarang. The system is suitable to display distance and travel time predictions for recommendations from the order of five deliveries by applying the Dijkstra algorithm method. The process that is carried out by the system, calculates the distance using Haversine formula. Thus, the travel time is obtained bases on congestion parameters. In Addition, besides the API is able to visualize the route of each destination from the catering location point.

Keywords: Dijkstra, Haversine Formula, PHP, Shortest Path, Artificial Intelligence. 


\section{PENDAhuluan}

Pangan merupakan usaha yang prospektif di Indonesia, sehingga perkembangan pangan dalam bidang industri menghasilkan minat untuk menekuni bisnis bidang ini. Bisnis katering saat ini cukup banyak (Harahap \& Khairina, 2017) Beberapa faktor seperti faktor manajemen yang masih sederhana, strategi pemasaran dan berpindahnya konsumen untuk mencari alternatif produsen lain menyebabkan katering kurang mampu bertahan lama (Budihartono, 2016). Kurangnya pelayanan yang diberikan seperti konsumen tidak merasa puas atas keterlambatan dalam pengantaran makanan sehingga kualitas makanan menjadi berkurang (Kamil, Anra, \& Sastypratiwi, 2015). Manajemen waktu juga harus diperhatikan baik dalam satu kali pengantaran menggunakan satu kendaraan agar dapat menghemat bahan bakar serta dari segi jumlah armada yang digunakan (Wijayanti, Prihandono, \& Kusnandar, 2015). Setiap jarak antar pabrik tentu berbeda namun untuk mengejar waktu jam makan karyawan agar tidak adanya keterlambatan diperlukan perhitungan jarak terpendek untuk memilih jalur terbaik (Prianto \& Kusnadi, 2018). Pemilihan jarak terpendek dihitung dari titik awal pengiriman titk pengantaran pabrik yang mana untuk meminimalisir waktu pengantaran katering pabrik di jam makan karyawan.

Penentuan jarak terpendek dilakukan dengan menggunakan peta yang sudah ada (Gonzalez, 2016) dengan cara memilih jalur terbaik dan terpendek dari titik awal ke titik tujuan, sehingga didapatkan hasil yaitu waktu tempuh perjalanan dan urutan pengantaran yang mana terlebih dahulu diantar (Junanda, 2016). Namun hal tersebut dirasa kurang maksimal karena memakan waktu untuk menentukan sendiri dari jalur jalur yang ada dan memperkirakan sendiri perhitungan jarak terpendek dari tempat asal ke tempat yang dituju (Effensi \& Rosmala, 2018). Hal tersebut dikarenakan permasalahan yang muncul seperti pemutusan jalur terpendek dengan adanya kegiatan masyarakat, kemacetan, atau jalan rusak (Cantona, Fauziah, \& Winarsih, 2020). Untuk itu diperlukan sistem yang dapat menentukan jarak terpendek dari titik asal ke titik tujuan untuk dapat membantu menemukan rute terpendek dan terbaik (Ismantohadi \& Iryanto, 2018). Dalam hal ini digunakan algoritma Dijkstra dalam penentuan jarak terpendek tersebut dengan menerapkan Haversine formula yang diterapkan pada penentuan pengantaran katering dari titik awal yaitu rumah katering dan titik tujuan yaitu lima pabrik yang lokasinya berada di sekitar rumah katering tersebut yang mana masih di dalam satu kota yang sama yaitu kota Cikarang. Studi kasus dari penelitian ini secara langsung diambil dari satu perusahaan katering di kota Cikarang, kemampuan dari katering tersebut adalah lima pengantaran dalam satu waktu. Permasalahan utama dari perusahan katering tersebut adalah menentukan urutan pengantaran, hal mana kendala kondisi jalan dalam hala ini kemacetan jalan setiap waktu berbeda, sehingga waktu pengiriman sangat berhubungan dengan penjadwalan. Oleh karena itu diperlukan sistem optimasi penjadwalan untuk mendapatkan waktu optimum dalam pengantaran katering berdasarkan rute atau jarak tempuh terpendek serta meminimalisir waktu pengantaran katering di jam makan siang pabrik di satu kota untuk tujuan lokasi pabrik yang berada di sekitaran lokasi rumah pabrik.

Setiap jarak antar pabrik tentu berbeda namun untuk mengejar waktu jam makan karyawan agar tidak adanya keterlambatan diperlukan perhitungan jarak terpendek untuk memilih jalur terbaik (Prianto \& Kusnadi, 2018). Algoritma Dijkstra digunakan sebagai metode untuk memecahkan permasalahan pencarian rute terpendek dengan memperhatikan kondisi jalan yang ada.Dengan menerapkan Haversine formula untuk membantu menghitung jarak antara titik di permukaan Bumi menggunakan latitude dan longitude yang ada. Penelitian ini bertujuan untuk membangun sistem optimasi 
penjadwalan untuk mendapatkan waktu optimum dalam pengantaran katering berdasarkan rute atau jarak tempuh terpendek dengan menerapkan algotima Dijkstra dan Haversine formula, serta sistem dapat menampilkan model lintasan terpendek dan waktu yang dibutuhkan dalam pengantaran katering menuju setiap lokasi pabrik.

\section{METODE PENELITIAN}

Penelitian dilakukan di kota Cikarang yang mana membutuhkan data jalanan, persimpangan yang ada, serta info jalur satu arah pada kota tersebut. Proses selanjutnya adalah mengolah data tersebut untuk dapat digambar. Data latitude dan longitude dari map sangat dibutuhkan untuk proses penggambaran lokasi pabrik untuk selanjutnya dilakukan proses intersection dengan batas wilayah kota Cikarang. Data yang telah masuk lalu diproses dengan menghitung jarak tempuh kendaraan. Informasi jarak di gunakan untuk mengetahui waktu yang optimum menuju lokasi pabrik. Status kemacetan diputuskan dengan menyesuaikan nilai kecepatan kendaraan dengan tabel klasifikasi jalan. Informasi ini tertuju pada pihak pengguna.

Proses selanjutnya adalah melakukan rancang bangun sistem untuk satu kali pengantaran makanan dari satu perusahaan katering menuju ke banyak pabrik. Sistem mengolah data jarak, dan waktu tempuh setiap tujuan. Terdapat parameter bobot kemacetan untuk menghasilkan urutan rekomendasi pengantaran yang didahulukan. Titik $A$ yaitu lokasi awal katering berada, menuju beberapa pabrik dengan notasi yang berbeda yaitu ( $P_{1}$, $\left.P_{2}, P_{3}, \ldots, P_{n}\right)$.

Pada Gambar 1 dijelaskan bahwa katering sebagai titik awal lokasi mencari urutan lokasi tujuan yaitu beberapa pabrik yang tidak ditentukan jumlahnya (Pabrik 1 , Pabrik 2, ... Pabrik n) dimana penentuan urutan diilakukan berdasarkan waktu tempuh paling optimum.

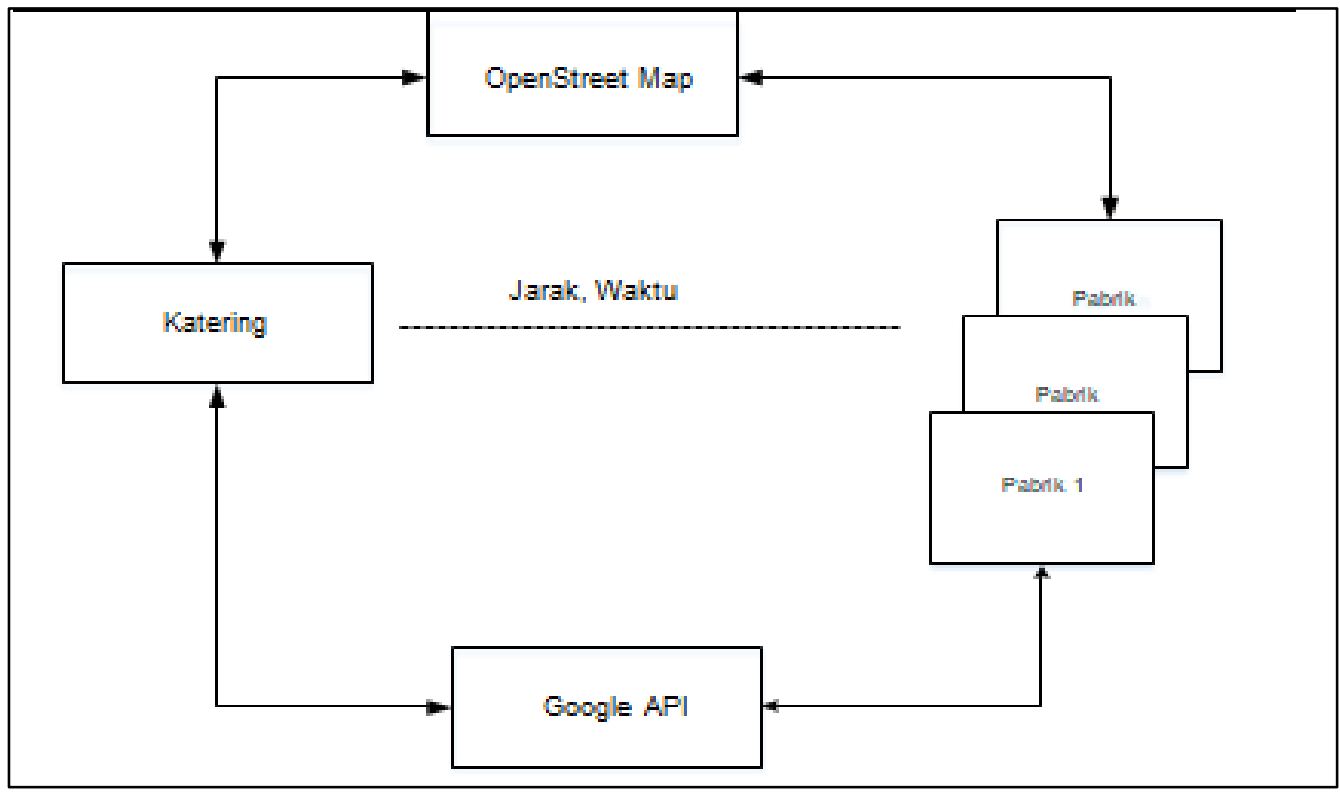

Gambar 1. Quick Design Proses Kerja Sistem yang Dibangun 


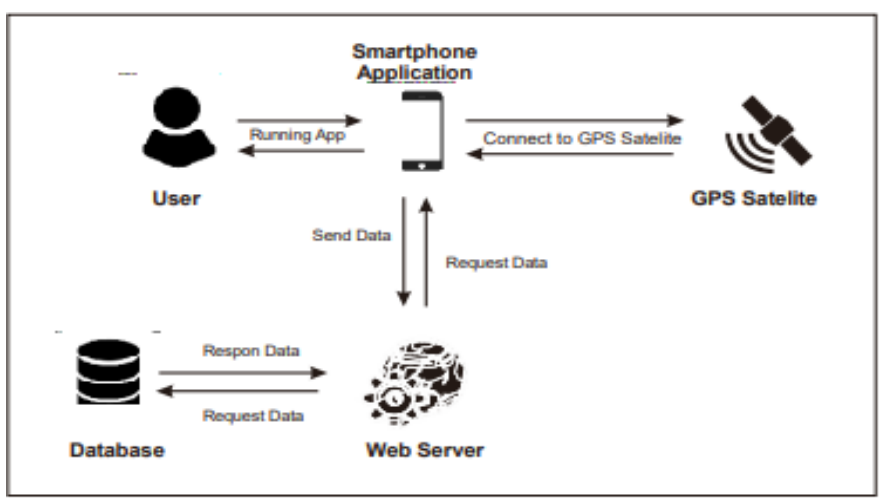

\section{Gambar 2. Skema Umum Perancangan Sistem Penentuan Jarak}

Pada Gambar 2 dijelaskan bahwa sistem diimplementasikan pada mobile device sebagai client dan web application sebagai server. Setelah GPS menerima transmisi sinyal satelit dan mendapatkan koordinat user, user kemudian diarahkan untuk memasukkan tujuan secara manual sehingga Cloud Database membaca data besaran koordinat latitude dan longitude. Setelah itu dilakukan proses perhitungan Algoritma Dijkstra untuk mendapatkan rute terpendek. Input awal dan tujuan berupa node diproses dengan menghitungkan nilai Dijkstra dan nilai heuristic yang nodenya termasuk pada openset. Setelah itu dilakukan perhitungan dan didapat node yang dapat dimungkinkan untuk dilalui dan ditampilkan pada peta sebagai path terpilih. Logika Algoritma Dijkstra yaitu lokasi yang berdekatan dijadikan satu simpul pada graf sedangkan jalan yang berpotongan secara langsung dijadikan sisi dalam graf. Setelah membentuk model graf kemudian menentukan jarak terpendek menggunakan perhitungan Haversine. Haversine Formula digunakan untuk mengetahui jarak antar titik di permukaan Bumi dimana latitude dan longitude digunakan sebagai variabel masukan(Junanda, 2016) .

Gambar 3 merupakan flowchart keseluruhan sistem penerapan rute terpendek dengan tahapan sebagai berikut.

1. Pengguna melakukan pendataan lokasi pabrik-pabrik kemudian Geometry Location mengembalikan informasi spasial termasuk nilai koordinat dari lokasi yang dimasukkan oleh pengguna.

2. Sistem menampilkan lokasi awal dan tujuan beserta koordinat.

3. Dari koordinat lokasi awal dan tujuan yang telah didapat, sistem memproses dengan melakukan perhitungan jarak berdasarkan rumus Haversine formula dan menerapkan Algoritma Dijkstra untuk pencarian rute terpendek.

4. Sistem menampilkan data urutan pengantaran yang didahulukan, rute pada peta dan disertakan jarak, waktu tempuh pada antarmuka aplikasi smartphone.

Gambar 4 merupakan subproses dari pendataan lokasi pabrik. Pendataan disini dimaksudkan untuk mengetahui data spasial berupa koordinat setiap pabrik sebelum memulai aplikasi pada smartphone.

1. Data yang dibutuhkan yaitu nama pabrik, alamat lokasi pabrik beserta titik koordinat lokasi pabrik.

2. Koordinat didapat dari Google API dengan proses geocoding. Untuk jumlah data yang dimasukkan dan disimpan pada sistem adalah minimal satu dan tidak ada batasan maksimum. 
Algoritma Dijkstra untuk Penentuan Jarak Tempuh Terpendek Pengantaran Katering Pabrik

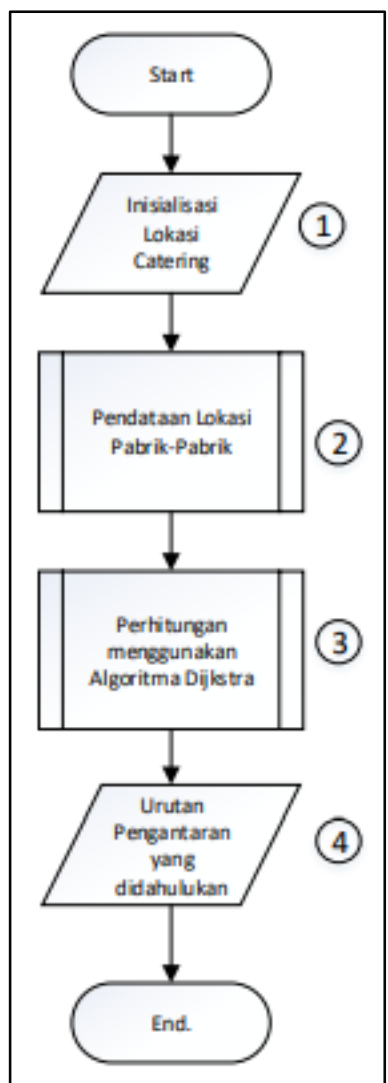

Gambar 3. Flowchart Sistem Penerapan Rute Terpendek

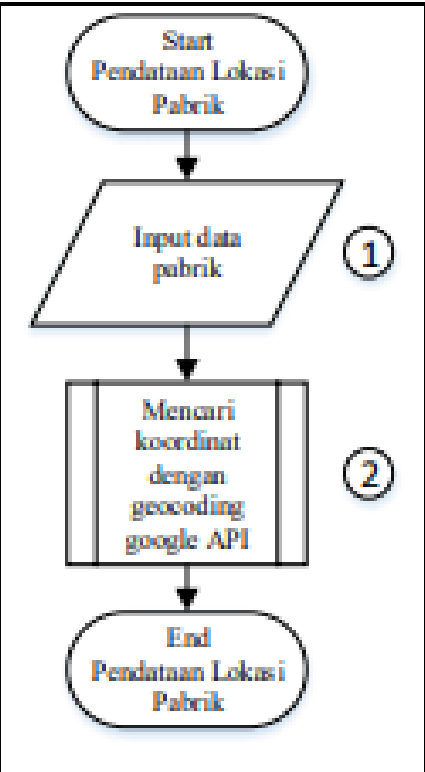

Gambar 4. Flowchart Pendataan Lokasi Pabrik 


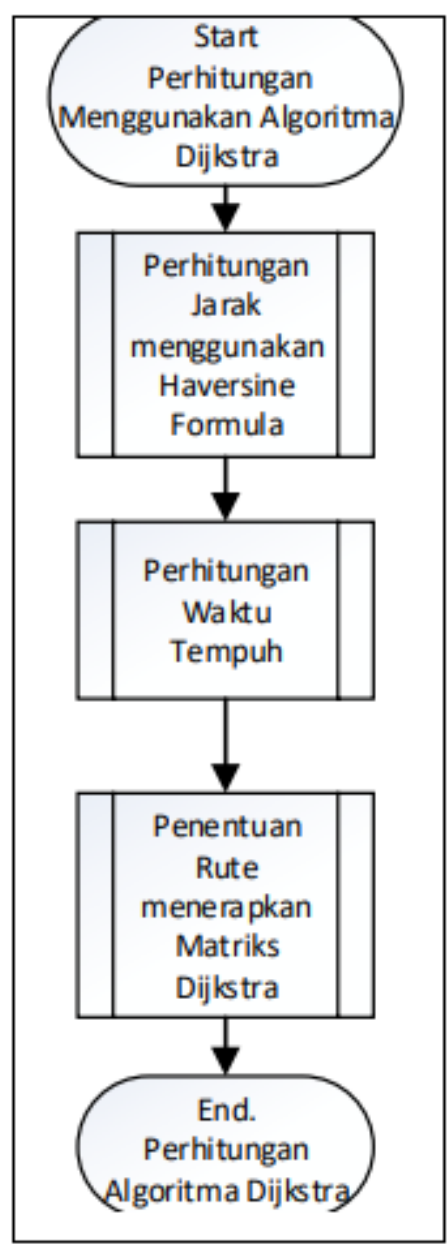

\section{Gambar 5. Flowchart Perhitungan Menggunakan Algoritma Djikstra}

Gambar 5 yang merupakan flowchart subproses perhitungan algoritma dijkstra. Sebelum sampai pada penentuan rute, ada beberapa tahapan untuk menghasilkan keluaran sistem yang diharapkan. Jarak diperhitungkan menggunakan Haversine formula yang merupakan salah satu persamaan akurat untuk menentukan jarak antara titik - titik bumi dengan memperhitungan lengkung bumi untuk penjelasannya dapat dilihat pada Gambar 6 . Setelah didapatkan jarak tempuh, perhitungan waktu tempuh dapat dimulai dengan dipengaruhi bobot kemacetan. Algoritma Dijkstra dapat merekomendasikan lintasan terpendek berdasarkan bobot waktu tempuh yang didapat dengan menerapkan matriks Dijkstra.

Pada Gambar 6 dijelaskan mengenai proses perhitungan jarak tempuh menggunakan persamaan Haversine formula dengan parameter katering dan pabrik-pabrik yang dituju. Variabel yang telah diinisialisasikan dengan $\mathrm{x}$ dan $\mathrm{y}$ adalah koordinat latitude dan longitude. Pada titik awal katering divariabelkan sebagai $\mathrm{x} 1, \mathrm{y} 1$ dan koordinat pabrik diinsialisasikan sebagai $\mathrm{x} 2 \mathrm{n}$ dan $\mathrm{y} 2 \mathrm{n}$ karena jumlah pabrik tidak dibatasi. Proses perhitungan jarak dilakukan dari node terdekat lokasi awal dan node terdekat lokasi tujuan. Setelah mendapatkan koordinat, perhitungan dilakukan secara berulang dari tujuan pabrik awal hingga pabrik ke- $n$. 


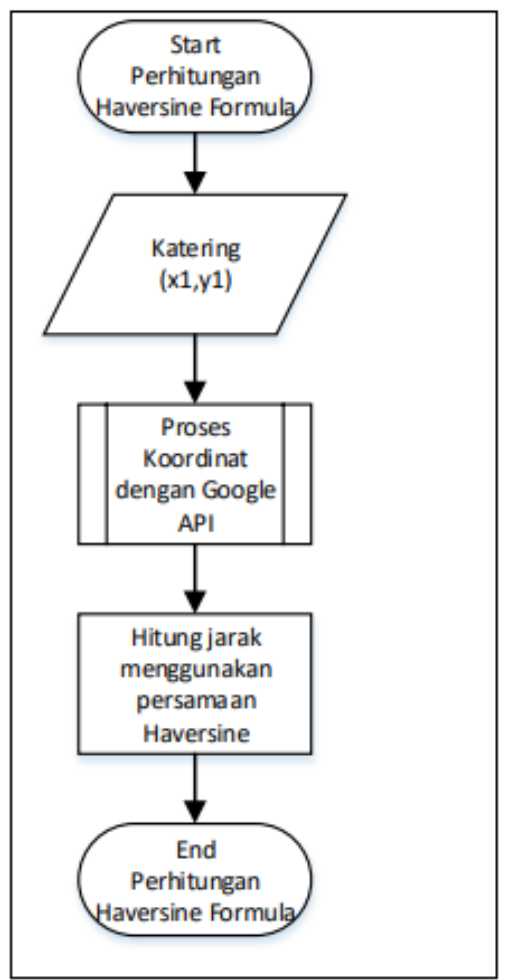

Gambar 6. Flowchart Perhitungan Haversine Formula

\section{HASIL DAN PEMBAHASAN}

\subsection{Studi Kasus}

Pada subbab ini dilakukan studi kasus untuk mencari jarak tempuh, waktu tempuh, dan perhitungan matriks dijkstra. Pada kasus ini dilakukan satu titik lokasi perusahaan katering dengan pengantaran menuju dua perusahaan pabrik untuk diketahui mana yang dapat didahulukan pengantarannya. Berikut ini adalah tahapan-tahapan yang dibahas dalam studi kasus ini.

1. Mencari jarak tempuh setiap node.

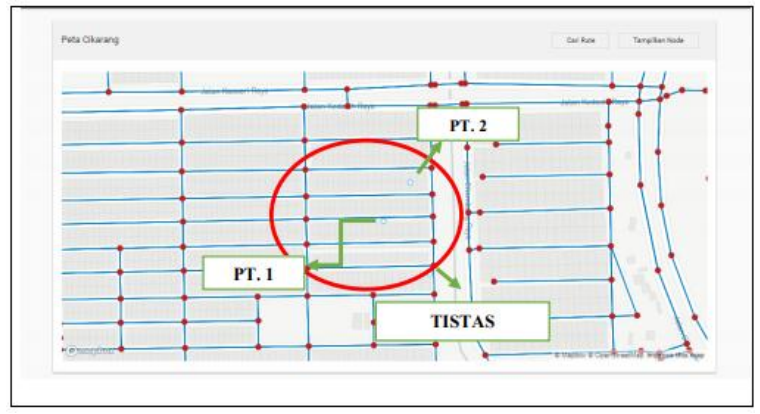

\section{Gambar 7. Pencarian Jarak Tempuh Setiap Node}

Gambar 7 merupakan tampilan peta kota Cikarang yang didalamnya terdapat gambar anak panah berwarna hijau menunjukan titik lokasi Tistas sebagai lokasi awal katering. PT1 dan PT2 merupakan lokasi tujuan. Persimpangan jalan pada peta disebut node dimana node node tersebut ditandai oleh titik merah pada tampilan peta. 
2. Tampilan Peta yang Diperbesar

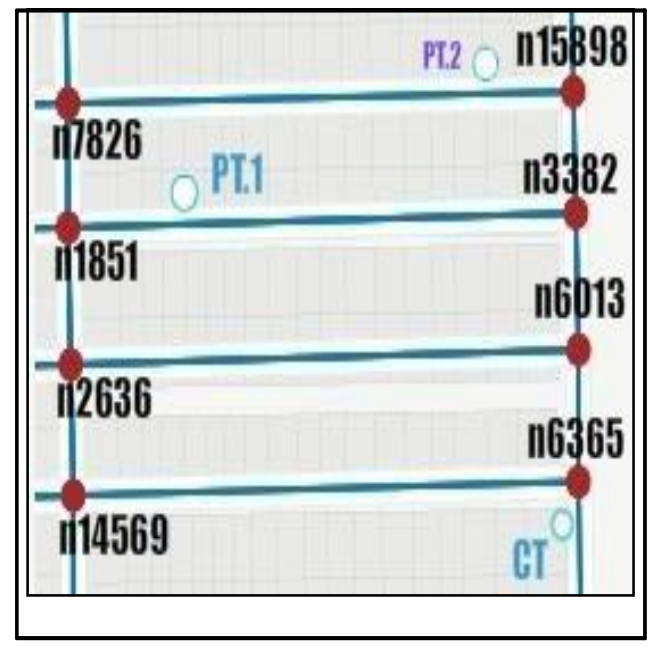

Gambar 8. Peta yang Diperbesar

Gambar 8 merupakan tampilan peta pada Gambar 7 yang telah diperbesar sehingga nama-nama node terlihat jelas. Sebelum dilakukan tahapan proses pencarian jarak antar node terdapat delapan node yang terdeteksi yaitu N6365, N14569, N2636, N1851, N6013, N3382, N15898.

Tabel 1. Inisialisasi Penamaan Node

\begin{tabular}{|c|c|}
\hline Nama node asli & Inisialisasi \\
\hline N6365 & a \\
\hline N6013 & b \\
\hline N3382 & c \\
\hline N14569 & d \\
\hline N15898 & e \\
\hline N2636 & f \\
\hline N1851 & g \\
\hline N7862 & h \\
\hline
\end{tabular}

Tabel 1 merupakan inisialisasikan nama-nama node yang asli menjadi nama lain yaitu huruf abjad berurut, bertujuan untuk memudahkan saat penggambaran tabel proses matriks pencarian bobot terkecil setiap node yang masing-masing punya keterhubungan.

Tabel 2. Latitude dan Longitude Lokasi

\begin{tabular}{|c|c|c|c|c|}
\hline Perusahaan & Lokasi & Latitude & Longitude & $\begin{array}{c}\text { Node } \\
\text { Terdekat }\end{array}$ \\
\hline $\begin{array}{c}\text { Tistas Catering } \\
\text { (Start) }\end{array}$ & $\begin{array}{c}\text { Jalan Kedasih XI } \\
\text { blok G1 no.2C }\end{array}$ & -6.301847 & 107.163662 & $\mathrm{a}$ \\
\hline PT1 & $\begin{array}{c}\text { Jalan Kedasih VII } \\
\text { no.22 }\end{array}$ & -6.301295 & 107.163995 & $\mathrm{~g}$ \\
\hline PT2 & $\begin{array}{c}\text { Jalan Kedasih V } \\
\text { no.5 }\end{array}$ & -6.300991 & 107.164768 & $\mathrm{e}$ \\
\hline
\end{tabular}

Tabel 2 merupakan keterangan koordinat latitude dan longitude yang didapat dari sistem menggunakan Google geocoding. Setelah koordinat lokasi didapatkan, sistem mencari node yang paling dekat untuk dijadikan titik acuan lokasi node.Seperti pada kasus ini

$$
\text { MIND - } 115
$$


bahwa lokasi CT berdekatan dengan node a dan PT2 berdekatan dengan node e. Berikut dijelaskan perhitungan jarak tempuh menggunakan rumus Haversine Formula.

Tabel 3. Bobot Kemacetan

\begin{tabular}{|c|c|}
\hline Kondisi Jalan & Bobot \\
\hline Normal & 1 \\
\hline Ramai Lancar & 0.8 \\
\hline Macet & 0.65 \\
\hline Macet Parah & 0.4 \\
\hline
\end{tabular}

Tabel 3 merupakan penjelasan setiap nilai bobot kemacetan. Bobot ruas jalan didapatkan dari asumsi ruas jalan yang memiliki kapasitas maksimal kendaraan yang terdiri dari kendaraan beroda empat dengan kecepatan rata - rata $40 \mathrm{~km} / \mathrm{jam}$. sehingga dipastikan pada ruas jalan akan terjadi kemacetan dengan begitu dapat dipilih salah satu jalur alternative dengan diiasumsikan perbedaan bobot setiap persimpangan jalan bahwa kondisi normal merupakan jalan lancar sehingga diberi bobot 1 yaitu $100 \%$ kondisi dari kecepatan rata-rata yang didata. Bobot 0.8 merupakan $80 \%$ kondisi jalan ramai lancar. Bobot 0.65 merupakan kondisi $65 \%$ dari kondisi normal yang berarti jalan macet dan 0.4 adalah macet parah.

Tabel 4. Jarak dan Hubungan Setiap Node

\begin{tabular}{|c|c|c|c|c|}
\hline \multirow[b]{2}{*}{ Node } & \multirow[b]{2}{*}{ Koordinat } & \multicolumn{2}{|c|}{ Hubungan } & \multirow{2}{*}{$\begin{array}{l}\text { Jarak antar } \\
\text { node }(\mathrm{km})\end{array}$} \\
\hline & & Node & $\begin{array}{c}\text { Bobot } \\
\text { Kemacetan }\end{array}$ & \\
\hline \multirow{2}{*}{$a$} & \multirow{2}{*}{$\begin{array}{l}-6.301840782165527 \\
107.16505432128906 \\
\end{array}$} & $\mathrm{~b}$ & 0.4 & 0.03 \\
\hline & & $\mathrm{h}$ & 1 & 0.158 \\
\hline \multirow{3}{*}{$b$} & \multirow{3}{*}{$\begin{array}{l}-6.301568984985452 \\
107.16505432128906 \\
\end{array}$} & $\mathrm{C}$ & 0.4 & 0.031 \\
\hline & & $\mathrm{g}$ & 0.65 & 0.159 \\
\hline & & $a$ & 0.65 & 0.03 \\
\hline \multirow{3}{*}{ c } & \multirow{3}{*}{$\begin{array}{c}-6.330718040466309 \\
107.1871109008789\end{array}$} & $d$ & 1 & 0.028 \\
\hline & & $f$ & 0.4 & 0.159 \\
\hline & & $\mathrm{b}$ & 0.8 & 0.031 \\
\hline \multirow[b]{2}{*}{$d$} & -6.301036357879639 & $\mathrm{e}$ & 0.4 & 0.158 \\
\hline & 107.1650390625 & $f$ & 1 & 0.028 \\
\hline \multirow[b]{2}{*}{ e } & -6.309691905975342 & $d$ & 0.4 & 0.158 \\
\hline & 107.1411890930175781 & $f$ & 0.8 & 0.028 \\
\hline \multirow{3}{*}{$f$} & \multirow{3}{*}{$\begin{array}{r}-6.311672687530518 \\
107.14118194580078 \\
\end{array}$} & $\mathrm{e}$ & 0.65 & 0.028 \\
\hline & & $\mathrm{C}$ & 0.65 & 0.159 \\
\hline & & $\mathrm{g}$ & 0.65 & 0.031 \\
\hline \multirow{3}{*}{$g$} & \multirow{3}{*}{$\begin{array}{c}-6301599502563477 \\
107.16361236572266\end{array}$} & $\mathrm{~b}$ & 1 & 0.159 \\
\hline & & $f$ & 0.65 & 0.031 \\
\hline & & $\mathrm{h}$ & 0.8 & 0.03 \\
\hline \multirow[b]{2}{*}{$\mathrm{h}$} & -6.296785831451416 & a & 0.65 & 1.5 \\
\hline & 107.15249633789062 & $g$ & 1 & 0.03 \\
\hline
\end{tabular}


Tabel 4 yang berisikan hubungan setiap node dan bobot kemacetan yang telah ditentukan dari sistem. Jarak didapat dari perhitungan yang telah dicontohkan sebelumnya. Berikut tahapan-tahapan Pencarian rute terpendek dan waktu tempuh dengan Algoritma Dijkstra menggunakan bobot kemacetan.

1. Menentukan kecepatan rata-rata kendaraan .

2. Menghitung matriks Dijkstra set node awal N6365 (lokasi katering)

3. Perhitungan bobot waktu tempuh (jam)

4. Konversikan waktu tempuh dari jam menjadi menit

Selanjutnya nilai bobot kemacetan antara node a dengan node $\mathrm{b}$ adalah 0.4 dan jarak yang didapat adalah $0.03 \mathrm{~km}$. Setelah waktu tempuh antar node didapat, selanjutnya dilakukan penentuan rute terpendek menggunakan matriks dijkstra. Berikut dijabarkan terlebih dahulu hasil waktu tempuh yang telah diperhitungkan yang dapat dilihat pada Tabel 5.

Tabel 5. Waktu Tempuh Seluruh Node

\begin{tabular}{|c|c|c|c|c|}
\hline $\begin{array}{c}\text { Node } \\
\text { keberangkatan }\end{array}$ & Node tujuan & $\begin{array}{c}\text { Bobot } \\
\text { Kemacetan }\end{array}$ & $\begin{array}{c}\text { Jarak } \\
\text { tempuh }\end{array}$ & $\begin{array}{l}\text { Waktu } \\
\text { tempuh }\end{array}$ \\
\hline \multirow[b]{2}{*}{$a$} & $\mathrm{~b}$ & 0,4 & 0,03 & 0,1125 \\
\hline & $\mathrm{C}$ & 1 & 0,158 & 0,237 \\
\hline \multirow{3}{*}{ b } & $\mathrm{C}$ & 0,4 & 0,031 & 0,11625 \\
\hline & $\mathrm{g}$ & 0,65 & 0,159 & 0,366923 \\
\hline & a & 0,65 & 0,03 & 0,069231 \\
\hline \multirow{3}{*}{ C } & $d$ & 1 & 0,028 & 0,042 \\
\hline & $f$ & 0,4 & 0,159 & 0,59625 \\
\hline & $b$ & 0,8 & 0,031 & 0,058125 \\
\hline \multirow[b]{2}{*}{ d } & $\mathrm{e}$ & 0,4 & 0,158 & 0,5925 \\
\hline & $\mathrm{C}$ & 1 & 0,028 & 0,042 \\
\hline \multirow[b]{2}{*}{ e } & d & 0,4 & 0,158 & 0,5925 \\
\hline & $f$ & 0,8 & 0,028 & 0,0525 \\
\hline \multirow{3}{*}{$f$} & $\mathrm{e}$ & 0,65 & 0,028 & 0,064615 \\
\hline & $\mathrm{C}$ & 0,65 & 0,159 & 0,366923 \\
\hline & $\mathrm{g}$ & 0,65 & 0,031 & 0,071538 \\
\hline \multirow{3}{*}{$g$} & $b$ & 1 & 0,159 & 0,2385 \\
\hline & $f$ & 0,65 & 0,031 & 0,071538 \\
\hline & $\mathrm{h}$ & 0,8 & 0,03 & 0,05625 \\
\hline \multirow[b]{2}{*}{$\mathrm{h}$} & $a$ & 0,65 & 1,5 & 3,461538 \\
\hline & $\mathrm{g}$ & 1 & 0,03 & 0,045 \\
\hline
\end{tabular}

Tabel 5 merupakan hasil waktu tempuh seluruh node yang telah didapat dari perhitungan bobot tempuh. Dimana parameternya terdapat node keberangkatan menuju masing- 
masing titik tujuan. Titik tujuan tersebut adalah node yang terhubung. Waktu tempuh yang didapat tersebut merupakan bahan yang diolah pada matriks dijkstra.

Tabel 6. Hasil Pengujian Pengantaran Katering Pabrik

\begin{tabular}{|c|c|c|c|c|c|c|c|c|c|}
\hline \multicolumn{2}{|c|}{ Pengujian } & \multicolumn{2}{|c|}{ Koordinat Katering } & \multicolumn{3}{|c|}{$\begin{array}{l}\text { Koordinat } \\
\text { Pabrik }\end{array}$} & \multirow{2}{*}{$\begin{array}{c}\text { Jarak } \\
\text { Tempuh } \\
\text { (km) }\end{array}$} & \multirow{2}{*}{$\begin{array}{l}\text { Waktu } \\
\text { Tempuh } \\
\text { (menit) }\end{array}$} & \multirow{2}{*}{$\begin{array}{c}\text { Hasil } \\
\text { Urutan } \\
\text { ke- }\end{array}$} \\
\hline & \multirow{6}{*}{$\begin{array}{l}\text { Tistas } \\
\text { Catering } \\
\text { (start) }\end{array}$} & Latitude & Longitude & Nama Pabrik & Latitude & Longitude & & & \\
\hline & & $\begin{array}{l}- \\
6.3019297\end{array}$ & $\begin{array}{l}107.16500840 \\
000003\end{array}$ & $\begin{array}{l}\text { PT Supernova } \\
\text { Flexible Packaging } \\
\text { Cikarang Plant }\end{array}$ & $\begin{array}{l}- \\
6.3098703,1 \\
07\end{array}$ & $\begin{array}{l}107.160201599 \\
99994\end{array}$ & 1.58 & 3.25 & 2 \\
\hline & & $\begin{array}{l}- \\
6.3019297\end{array}$ & $\begin{array}{l}107.16020159 \\
999994\end{array}$ & $\begin{array}{l}\text { PT. Adaywinsa } \\
\text { Electrical and } \\
\text { Power }\end{array}$ & -6.3072119 & $\begin{array}{l}107.162996799 \\
99997\end{array}$ & 1.64 & 3.17 & 1 \\
\hline & & $\begin{array}{l}- \\
6.3019297\end{array}$ & $\begin{array}{l}107.16020159 \\
999994\end{array}$ & $\begin{array}{l}\text { PT. Bina Niaga } \\
\text { MultiUsaha }\end{array}$ & -6.3097986 & $\begin{array}{l}107.155240699 \\
99992\end{array}$ & 1.91 & 3.75 & 4 \\
\hline 1 & & $-\overline{6.3019297}$ & $\begin{array}{l}107.16020159 \\
999994\end{array}$ & $\begin{array}{l}\text { PT. Dinamika } \\
\text { Makmur Sentosa }\end{array}$ & $\begin{array}{l}- \\
6.312513999 \\
99\end{array}$ & $\begin{array}{l}107.154426100 \\
00002\end{array}$ & 1.74 & 3.60 & 3 \\
\hline & & $\begin{array}{l}- \\
6.30192 \\
97\end{array}$ & $\begin{array}{l}107.16020159 \\
999994\end{array}$ & PT.Asahi Indonesia & -6.3161217 & $\begin{array}{c}107.179800800 \\
00007\end{array}$ & 3.17 & 6.70 & 5 \\
\hline
\end{tabular}

Terdapat 5 lokasi pabrik yang dimasukkan dalam daftar tujuan pengantaran katering di waktu yang sama. Sehingga dicarikan urutan pabrik mana yang pertama sampai terakhir untuk diantarkan makanannya. Hasil pengujian pertama didapatkan urutan pertama yaitu PT Supernova Flexible Packaging Cikarang Plant, urutan kedua adalah PT Supernova Flexible Packaging Cikarang Plant, urutan ketiga adalah PT. Bina Niaga MultiUsaha, PT. Dinamika Makmur Sentosa dan pengantaran terakhir adalah PT.Asahi Indonesia. Urutan didapatkan berdasarkan jarak tempuh dan waktu tempuh dimana urutan pertama adalah waktu dan jarak yang bernilai kecil. Gambar 9 merupakan hasil implementasi pada smartphone berdasarkan pengujian yang ada pada Tabel 6. Dimana urutan pertama hingga akhir sama seperti keterangan Tabel 6. 


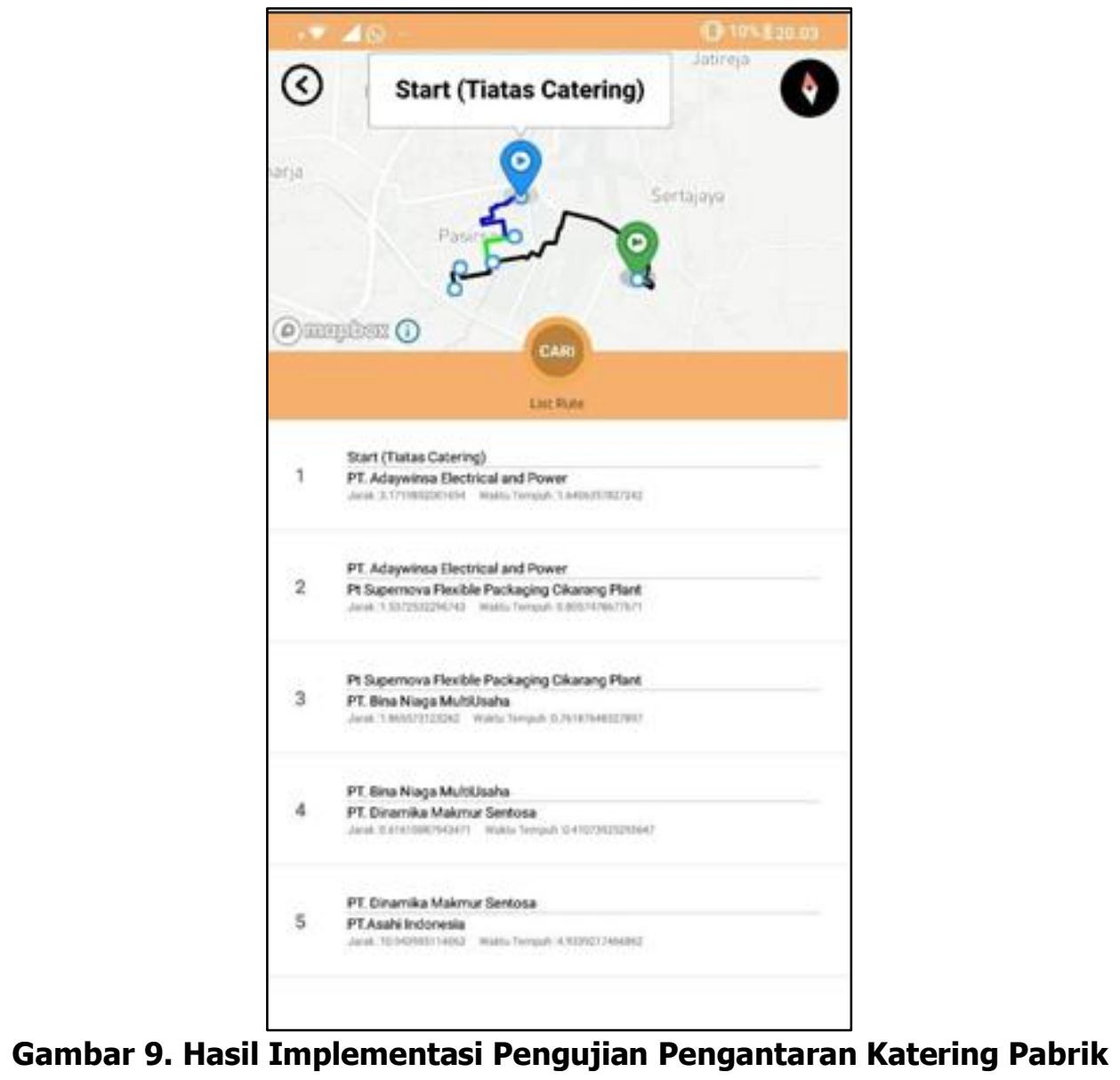

\section{KESIMPULAN}

Dari hasil pengujian sistem didapatkan kesimpulan yaitu sistem dapat menerapkan Algoritma Dijkstra untuk optimasi penjadwalan berdasarkan jarak tempuh terpendek dengan perhitungan jarak menggunakan Haversine Formula. Berdasarkan perancangan studi kasus yang telah diterapkan pada sistem, sistem berhasil memberi alternatif antrian pengantaran ke beberapa pabrik dengan maksimal lima pabrik dalam satu kali pengantaran, dimana urutan selanjutnya dijadikan pengantaran selanjutnya. Setelah di masukkan dua lokasi yang berdekatan, sistem menunjukkan kegagalan yaitu sistem tidak dapat melakukan proses perhitungan sehingga hasil yang didapat adalah jarak tempuh dengan nilai $999999.0 \mathrm{~km}$ dan waktu tempuh 99999.0 menit. Dikarenakan pada kasus ini lokasi tujuan sangat berdekatan sehingga sistem hanya membaca satu koordinat dari node terdekat tersebut.

\section{DAFTAR RUJUKAN}

Budihartono, E. (2016). Penerapan Algoritma Dijkstra untuk Sistem Pendukung Keputusan Bagi Penentuan Jalur Terpendek Pengiriman Paket Barang pada Travel. Teknik Komputer Politeknik Harapan Bersama. 
Cantona, A., Fauziah, F., \& Winarsih, W. (2020). Implementasi Algoritma Dijkstra pada Pencarian Rute Terpendek ke Musem di Jakarta.

Effensi, I., \& Rosmala, D. (2018). Pengukuran Tingkat Keakurasian Jarak dengan Menerapkan Algoritma Dijkstra pada Sistem Zonasi.

Gonzalez, A. (2016). Measurement of Areas on A Sphere using Fibonnaci and Latitude Longitude Lattices.

Harahap, M. K., \& Khairina, N. (2017). Pencarian Jalur Terpendek dengan Algoritma Dijkstra. Jurnal \& Penelitian Teknik Informatika.

Ismantohadi, E., \& Iryanto. (2018). Penerapan Algoritma Dijkstra Untuk Penentuan Jalur Terbaik Evakuasi Tsunami - Studi Kasus : Kelurahan Sanur Bali. Jurnal Teknologi Terapan.

Junanda, B. (2016). Pencarian Rute Terpendek Menggunakan Algoritma Dijkstra Pada Sistem Infirmasi Geografis Pementaan Statiun Pengisian Bahan Bakar Umum . Universitas Negeri Padang.

Kamil, M. I., Anra, H., \& Sastypratiwi, H. (2015). Rancang Bangun Aplikasi Pencarian Rute Terpendek Lokasi Wisata Kuliner Kota Pontianak Berbasis Mobile.

Prianto, C., \& Kusnadi, M. (2018). Penerapan Algoritma Dijktra untuk Menentukan Rute Terbaik pada Mobile E-Parking Berbasis Sistem Informasi Geografis.

Wijayanti, S., Prihandono, B., \& Kusnandar, D. (2015). Mencari Lintasan Terpendek dan Optimalisasi Kendaraan Pengangkut Sampah di Pontianak. 